\title{
O JEZIKU KAJKAVSKOGA PJESNIŠTVA ĐURĐE JANDRIŠ-PARAĆ
}

\author{
Boris Kuzmić, Zagreb
}

\section{Sažetak}

U radu se analizira jezik kajkavske pjesničke zbirke Turopole moje lepo: joa i ti-jeno zanaviek (2005.) autorice Đurđe Jandriš-Parać (1945. g.). Analiza će pokazati u kojoj mjeri autoričin suvremeni kajkavski književni jezik uključuje dijakroniju (poznavanje jezika stare kajkavske književnosti) i sinkroniju (suvremene turopoljske govore, pogotovo pleški govor, čija je autorica izvorna govornica).

Ključne riječi: kajkavsko pjesništvo; kajkavski književni jezik; Đurđa Jandriš-Parać; Pleso, Turopolje

U ovome radu analizirat će se jezik pjesničke zbirke Turopole moje lepo: joa i ti-jeno zanaviek (2005. autorice Đurđe Jandriš-Parać. Analizi se neće pristupiti isključivo kao samosvojnome tekstu, nego će se uključiti i poznavanje jezika stare kajkavske književnosti kao i suvremenih turopoljskih govora čija je autorica izvorna govornica. Čini mi se zanimljivim istražiti autoričin jezik zato što može pokazati koliko prati književnu tradiciju, koliko suvremene dijalektalne crte koje su zajedničke i većini kajkavskih govora, a koliko je njezin pjesnički izričaj isključivo turopoljski. Da bi se moglo utvrditi koliko pisci pišu svojim materinskim govorom, potrebno bi bilo izraditi fonološki i morfološki opis njihova zavičajnog govora. U slučaju pjesnikinje Đurđe Jandriš-Parać riječ je o pleškome govoru koji zasad nema samostalne jezične analize, ali je djelomice obrađen u radovima istraživača turopoljskih govora, posebice onih Antuna Šojata (1982). Prema Šojatu (1982: 322), pleški govor pripada središnjoj skupini turopoljskih govora. Jezik Đurđe Jandriš-Parać analizira se na fonološkoj i morfološkoj razini zato što one najbolje zrcale tipične dijalektalne osobine, a one se uspoređuju 
s crtama drugih turopoljskih govora (Šojat 1982), ali se i odmjeravaju o jezik bogate kajkavske pisane baštine (Šojat 2009) ${ }^{1}$.

Pjesnikinja Đurđa Jandriš-Parać rođena je 1945. u selu Pleso kraj Velike Gorice. Osnovnu je školu pohađala u Velikoj Gorici, a srednju u Zagrebu. Učila je francuski i talijanski jezik u Parizu i Rimu. Na Filozofskom fakultetu Družbe Isusove diplomirala je filozofiju i religijsku kulturu. Danas živi u Plesu, a u svojoj sredini djeluje kao slikarica, kolekcionarka i pjesnikinja. Turopole moje lepo njezina je treća zbirka pjesama (prva kajkavska!) objavljena 2005. u izdanju SPARK-a ${ }^{2}$. U zbirci je sakupljeno tridesetak pjesama. U članku se uz primjere navode brojevi koji označavaju broj stranice u objavljenoj zbirci.

\section{Fonološke osobitosti}

Refleks šva uglavnom je e, npr. listek 23, melen 29, misel 11, 21, pameten 33 , počinek 25, 29, sejne 15, smisel 11, venčec 23. Autorica se koleba samo u nenaglašenom nesvršenom prezentu pomoćnoga glagola biti koji je poslužio za tvorbu perfekta: nisem smiela 41, sem bila 25, sem frkala 21, sem odrasla 25 , sejnala sem 23, sem spekla 59, sem sretna 25, zasadila sem 71, sem se zbudila 23 - sam čeprkala 21, iskala sam 21, restiepala sam 21. Iz primjera se vidi da je dominantan refleks $e$. Taj je refleks u staroj kajkavskoj književnosti najčešći, a zajednički je i sa stanjem u suvremenim turopoljskim govorima (Šojat 1982: 343-344, 2009: 15).

Samoglasnik a kada je kratak bilježi se s a, npr. baka 59, Japice 73, kak 69, maminom 25, ravnica 45, starinu 19, svadbe 35, vrapček 53. Kada je samoglasnik $a$ dug, tada se bilježi s dvoglasom oa ili samoglasnikom o, npr. čardoak 51, namoače 55, obroaslo 13, poači 39, soami 17, znoači 39, Zoagreb 47, zoate 27 ; roni (= hrani) 65 , strone 21 , vu nomi 23 . Autorica u bilježenju samoglasnika $\mathrm{u}$ istih riječi nije dosljedna, npr. droaga 25 - predrogi 19, joa 23, 25, 41 - jo 19 , vkroala 77 - fkrola 63 . U posljednjem se primjeru autoričina nedosljednost očituje i u bilježenju suglasnika $v / f$. U istraživanju turopoljskih govora Šojat (1982: 342) je zabilježio diftonški izgovor dugih samoglasnika koji je običniji u onih govora u kojima se refleks dugoga jata realizira kao dvoglas. Zanimljivo je istaknuti da je diftonški izgovor dugih samoglasnika tipičniji za zapadnu skupinu

\footnotetext{
${ }^{1}$ Građa se uspoređuje isključivo s radovima hrvatskoga dijalektologa i povjesničara hrvatskoga jezika Antuna Šojata (1928-2012.) koji je jedini, dosad, najiscrpnije opisao suvremene turopoljske govore i dao pregled glasova i oblika u jeziku stare kajkavske književnosti.

${ }^{2}$ SPARK je udruga umjetnika s područja grada Velike Gorice koja okuplja književnike, glazbenike i slikare.
} 
turopoljskih govora i zato mi se čini da je autoričina uporaba dvoglasa nastala pod utjecajem zapadne skupine turopoljskih govora. Zamjena samoglasnika $a \mathrm{u}$ prefiksu raz-relativno je česta u turopoljskih govora (Šojat 1982: 346), a razvidna u autoričinu pjesništvu, npr. rescvetena 23 , restiepala 21 , rezgalila 63 , rezlieva 61, rezlievam 15. Samo u jednom primjeru sačuvan je prefiks raz-: razmieče 61. U primjeru dej 33, 43 stanje je sukladno većini turopoljskih govora gdje $a$ ispred $j$ prelazi u $e$ (Šojat 1982: 342). U staroj kajkavskoj književnosti (Šojat 2009: 10) nalazimo samo oblike s a u spomenutim oblicima, tako da njegovu zamjenu s dvoglasom ili samoglasnikom $e$ smatram turopoljskim dijalektizmom.

U primjerima kapielica 35, premiečem 41, razmieče 61 i skrieče 51 dolazi do zamjene samoglasnika $e$ dvoglasom ie. Tu je pojavu Šojat (1982: 342) zabilježio u sjeverozapadnim turopoljskim govorima. U staroj kajkavskoj književnosti, osim u Pergošića i Vramca, takva pojava nije zabilježena (Šojat 2009: 11).

Refleks prednjega nosnoga samoglasnika redovito je e, npr. ime 33, mesec 37 , se 17 , te 19 , zela 35 . Isti je rezultat i u turopoljskih govora i u staroj kajkavskoj književnosti (Šojat 1982: 345, 2009: 10-11).

Refleks stražnjega nosnog samoglasnika redovito je $u$, npr. dušu 17, 57, gliblinu 19, grudu tvoju 25, kираји 35, moguče 23. Isti je rezultat i u turopoljskih govora i u staroj kajkavskoj književnosti (Šojat 1982: 346, 2009: 12-13). Autorica u nekoliko primjera na mjestu stražnjega nosnog samoglasnika rabi samoglasnik $i$ : glibline 21, gliblinu 19, gliboko 13. Navedenu pojavu Šojat nije zabilježio u suvremenim turopoljskim govorima.

Samoglasnik -i gubi se u prefiksu iz-, npr. zgubim 63, zišla 29, zlieje 27, zlubim 63, zmolim 63, zreči 27, zvira 11. U staroj kajkavskoj kniževnosti ta je pojava rijetka, ali je redovita u turopoljskim govorima (Šojat 1982: 351, 2009: 17-18).

Samoglasnik o mijenja se u a u primjerima rada sam čeprkala 21 i rada hodočasti 63; promjenu $o>$ e pratimo u prefiksu pro-, npr. preklije 15; promjenu $o>$ u primjerima kuliko 27, 39, muoramu 59, sedimu 23, tuliko 23; promjenu $o$ $>$ uo u primjerima duojdi 53, duoma 11, muoj 19, muoramu 59, stuoti 53, svuoj 25, škuolke 57, turopuolska 25. U jeziku stare kajkavske književnosti samoglasnik $o$ pretežito je neizmijenjen ${ }^{3}$, a navedene promjene potvrđuju se u suvremenim turopoljskim govorima (Šojat 1982: 342, 348, 409).

Gubljenje samoglasnika $o$ na kraju riječi nalazim u primjerima kak 17, 21, 25, kam 17, 29, 63, nekak 27, tak 15, 29. U predzadnjem slogu samoglasnik o

\footnotetext{
${ }^{3}$ Među rijetkim unošenjem govornih crta u jezik stare kajkavske književnosti izdvaja se promjena pro- > pre- koja je relativno slabo zastupljena, dok je promjena $o>u$ u priloga kuliko i tuliko redovita (Šojat 2009: 11-12, 16).
} 
gubi se u primjerima negve 69, njegva 51. To je osobina zajednička jeziku stare kajkavske književnosti i suvremenih turopoljskih govora (RHKKJ 1995: 177, 1999: 309, Šojat 1982: 351, 2009: 17).

Refleks jata autorica bilježi dvojako. Kada je slog kratak, refleks jest $e$, npr. deklu 41, dragocena 57, kolena 69, lepota 51, lepote 23, mere 19, mesec 55, peva 13 , pleva 69 , razlejoana 13 , rescvetena 23 , seme 15 , večni 25 , venčec 23 , veter 53, zasenila 51. Kada je slog dug, refleks jest ie, npr. ciele 19, cvietju 23, diete 25, 59, dozrieva 17, naviek 17, oblieje 17, popieval 23, prelieva 17 , rezlieje 17 , rezlievam 15 , snieg 69 , svieta 21 , tielo 25 , vrieme 29 , zalievam 15 , zavliekel 57. Ikavski refleks jata javlja se u primjerima na plač me tira 29 i više nima ništa 47, nima mira 77. Istražujući turopoljske govore Šojat (1982: 345) je zabilježio refleks $e$ u kratkom i u dugom slogu, ali za dugi slog ustvrdio je da se "na području istočno od linije Trnje-Kurilovec-Kravarsko dugo jat reflektira monoftonškom varijantom [ẹ:], premda i unutar tog područja ima govora koji poznaju diftonšku realizaciju [iẹ] (...) Zapadno od te linije preteže diftonški izgovor. (Šojat 1982: 341). Glagol těrati zabilježen je s ikavskim refleksom, ali nema potvrda za isti refleks u prefiksu ně- u suvremenih turopoljskih govora (Šojat 1982: 345). U staroj kajkavskoj književnosti "rijetko je koji pisac kadšto označavao diftonški izgovor na mjestu e dvoslovom ie, kako su to često radili Pergošić i Vramec. (Šojat 2009: 15). Glagol těrati u staroj se kajkavskoj književnosti pretežito bilježio s ikavskim refleksom (Šojat 2009: 15). Međutim, valja reći da u istih leksema (oblici glagola děti, htěti, imenica leto / lieto u značenju godišnjeg doba, pridjev lep / liep) autorica nije dosljedna, npr. kam se to vrieme delo 29, dene 39, deneš 17 - vu se je diela 35; štel 47, 63, 69, štela 35, šteli su 19 - štiela 25; z proleča zelena v letu se zlati 45 - Jenu lietnu odvečerku na klupe sedeč 33; lepi 41 - liepo 17, 55. Kada imenica léto označava godinu, tada autorica isključivo rabi refleks ie, npr. Restiepala sam misel čez sa ova lieta 21, Sred pleškoga pola več duga lieta 35, zoajnu su došla huda lieta 39.

Slogotvorno $l$ dalo je $u$, npr. dugo 15, napuni 17, tuče 17. U staroj kajkavskoj književnosti ista je situacija ${ }^{4}$, a u suvremenim turopoljskim govorima moguć je i refleks $o$ (Šojat 1982: 346, 2009: 12).

Slogotvorno $r$ čuva se u primjerima brvno 65, čeprkala 21, drvena 39, frkala 21, smrt 71, srce 19, 23, zrcalom 63. U jeziku stare kajkavske književnosti pretežito nalazimo bilježenje slogotvornoga $r$ glasovnom sekvencom $e r^{5}$, a u govoru mnogih turopoljskih sela takvo e znatno se reducira (Šojat 2009: 14).

\footnotetext{
${ }^{4}$ Iznimku čine Vramčevi tekstovi i pokoje sporadično odstupanje.

${ }^{5}$ Iznimku čini Vramec koji ima nekoliko primjera sa sekvencom ar.
} 
Stezanje samoglasnika potvrđuje se primjerima ki bi je reči mogel 77, mega 71, memu 43, svega Jureka 63, ali ima primjera u kojima ono izostaje: moje 13, 23 , mojega 11, svoje 15, tvoje 13. U suvremenim turopoljskim govorima nalazimo potvrde za obje pojave (Šojat 1982: 350). U staroj kajkavskoj književnosti stegnuti oblici sporadične su pojave (Šojat 2009: 17).

U bilježenju početnoga glasa $h$ autorica nije dosljedna: u primjerima hižica 39, 65, hodeč 37, hodi 37, 59 glas $h$ se čuva, a u primjerima oče 29, 31, 69, 77, roni (= hrani) 65, roast (= hrast) 65 početno se $h$ gubi. U turopoljskih se govora početno $h$ najčešće gubi (Šojat 1982: 356). U središnjem slogu $h$ se mijenja u $j$ ili se čuva, npr. grieje 35, plejnata 33; orehnaču 59. U turopoljskih se govora središnje $h$ gubi ili zamjenjuje glasovima $v$ ili $j$ (Šojat 1982: 356). U završnom slogu $h$ nije sačuvano, npr. na pleče 47, po možđane 61, v ruka 25, (vu) Vukomeričke gorica 43. Ista je situacija i u turopoljskih govora (Šojat 1982: 356). H se mijenja $\mathrm{u}$ š ispred $t$ u oblicima glagola šteti (= htjeti), npr. štel 47, 63, 69, štela 35, šteli 19, štiela 25. Skupina $h v$ mijenja se u $f$ u primjeru foalu 33. Posljednje su dvije pojave razvidne i u turopoljskih govora (Šojat 1982: 357). U staroj kajkavskoj književnosti, bez razlike u položajima ili pripadnosti pojedinim suglasničkim skupinama, redovito se čuva etimološko $h$ (Šojat 2009: 27).

Protetsko $v$ potvrđuje se primjerima vučil 71, vuličkam 37, vuskem 37,vuz buku 33, vuz kanoal 59. To je osobina zajednička jeziku stare kajkavske književnosti i suvremenim turopoljskim govorima (Šojat 1982: 349, 2009: 16).

Zavšno se -l čuva, npr. misel 57, smisel 11, zibal 37, žal 35. Ista je situacija u staroj kajkavskoj književnosti i u suvremenim turopoljskim govorima (Šojat 1982: 359, 2009: 22-23).

Depalatalizacija glasa 1 redovito se provodi, npr. Luba 53, lubaf 27, lubav 13, 71, lude 33, pogrblena 39, pola 15, 35, strplivost 33, Turopole 13, 23, 27 , turopolsku 51, zalubleno 17, 41, zemle 21, zemlica 25, zemlinu 31, zemlu 25. U većini suvremenih turopoljskih govora izvršena je depalatalizacija glasa 1, a u staroj kajkavskoj književnosti puno je toga ovisilo o pojedinim položajima u riječi ili sufiksima koji će omogućiti ili ne provođenje depalatalizacije (Šojat 1982: 359, 2009: 22-24).

Suglasnik $\dot{n}$ realizira se samo u primjerima krošnje 37, krščenja 35, njegva mladost 51, proščenja 35, proščenju 63, v trnju 39. Autorica ovdje nije dosljedna $-\mathrm{u}$ istom primjeru potvrđuje se depalatalizirani oblik s $n$ (negva 47, negve 69), a u imenica s istim sufiksom -ja ili -je, ne doduše u istih riječi, povrđuju se primjeri s metatezom palatalnoga elementa kao jn (korejnem 13, siečajna 75, siečajne 75, svijne 65, škrijne 41, škrijnica 65). Depalatalizirani primjeri jesu knigami 21, spominali 33, spominam 19 - i oni nemaju potvrda s neizmijenjenim ń. Drugi depalatalizirani primjeri, kao što su nega 69 ili ž num 21, stoje u opreci 
prema jn, ako su dio prijedložnoga izraza gdje prijedlog završava samoglasnikom, npr. najnega 73, najnem 63, noajnu 33, 39, vujne 39, vu jnega 25, 41, vu jnu 41, zajnega 73. Autorica kadšto u pismu bilježi, a kadšto ne, jedinstveni izgovor prijedložnih izraza. U primjerima kojn i sejna autorica redovito provodi metatezu palatalnoga elementa, npr. kojnek 29, sejnala sem 23, sejne 15, 23, 37. U jeziku starije kajkavske književnosti broj potvrda za promjene ń $>n$, jn vrlo je malen (Šojat 2009: 24), a u suvremenim turopoljskim govorima to je redovita pojava (Šojat 1982: 360-361).

Refleks glasa $t$ ' u većini je kajkavskih govora dalo č, koji se fonetski i fonološki izjednačio s refleksom praslavenskoga glasa č. To je razvidno i u staroj kajkavskoj književnosti i u suvremenih turopoljskih govora (Šojat 2009: 29, 1982: 361), pa tako i u autoričinim pjesmama, npr. čutim 13, 27, moči 19, reči 15 , sieča 73 , siečajne 75 , več 15 .

U suglasničkoj skupini čl- posljednji suglasnik je ispao, npr. čovek 33, čoveku 39. U jeziku stare kajkavske književnosti oblik čovek potvrđuje se samo u Pergošića (RHKKJ 1985: 309).

Suglasnička skupina $\check{c} r$ - nije izmijenjena, npr. črnoga 67, črvi 29. Gotovo je ista situacija i u turopoljskim govorima (Šojat 1982: 362). U staroj kajkavskoj književnosti uglavnom se bilježi skupina čr-, osim u pisaca s kraja 18. i početka 19. stoljeća koji je zamjenjuju skupinom $\mathrm{cr}$ - pod utjecajem štokavske književnosti (Šojat 2009: 32).

Promjenu $d n>n$ nalazim u primjerima $v$ jene 21, jeno 25, jenoga 63 i jenu 33. Ta je promjena u jeziku stare kajkavske književnosti iznimno rijetka - za nju nalazimo tek nekoliko potvrda (Šojat 2009: 37). U suvremenim turopoljskim govorima provodi se redovito (Šojat 1982: 364, 405).

Promjena $k t>t$ zabilježena je u primjeru teru 47, 73. U suvremenih turopoljskih govora $k$ se čuva samo u obliku nekteri, a u staroj kajkavskoj književnosti oblik teri uopće nije potvrđen (Šojat 1982: 362, 2009: 36).

Promjenu $m n>v n$ nalazim u primjeru vnuogi 33. Promjena je zabilježena $\mathrm{u}$ staroj kajkavskoj književnosti (v. RHKKJ 1991: 681) i u suvremenim turopoljskim govorima (Šojat 1982: 362-363).

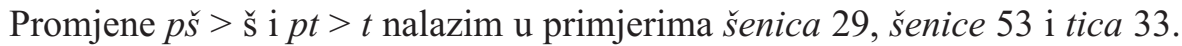
Te promjene nisu zabilježene u jeziku stare kajkavske književnosti, ali ih nalazimo u suvremenim turopoljskim govorima (Šojat 1982: 362, 2009: 36).

Suglasničke skupine skj i stj daju isti rezultat šč, npr. išče 11, 77, pritiščem 25, stiščem 25; krščenja 35, proščenja 35, proščenju 63. To je pojava zajednička jeziku stare kajkavske književnosti i suvremenih turopoljskih govora (Šojat 1982: 361, 2009: 34-35). 
$\mathrm{U}$ jednom se zabilježenom primjeru suglasnička skupina tr- mijenja u $d r$-: drči 67. Ista je pojava zabilježena u jeziku stare kajkavske književnosti i u turopoljskih govora (Šojat 1982: 363, RHKKJ 1985: 473).

Promjenu $v \check{c}>$ č nalazim u primjeru čera 29.

Promjenu $v n>n$ nalazim u primjeru nučicu 59.

Promjenu $v s>s$ nalazim u primjerima sa 13, 21, sake 17, 41, 61, saki 11, 23, se 25, sega 63, semu 21, si 27.

Promjenu $v z>z$ nalazim u primjerima zela 35, zeto 77. Toj promjeni, a $\mathrm{i}$ prethodnim trima promjenama zajednički je nazivnik - one se ne provode u staroj kajkavskoj književnosti ili su u njoj vrlo rijetke, a redovite su u suvremenim turopoljskim govorima (Šojat 1982: 357, 2009: 37).

Rotacizam nalazim u prezentu glagola moči, npr. more 39, ne morem 19, 61, 73, nemre 29, 69. To je osobina zajednička jeziku stare kajkavske književnosti i suvremenih turopoljskih govora (RHKKJ 1991: 683, Šojat 1982: 358).

Obezvučenje zvučnoga suglasnika na kraju riječi nalazim samo u primjeru vrak 33, kao i čuvanje zvučnoga suglasnika, npr. Zoagreb 47. Obezvučenje zvučnih suglasnika svojstveno je većini kajkavskih govora, tako i turopoljskih (Šojat 1982: 355), ali u staroj se kajkavskoj književnosti ne bilježi (Šojat 2009: 20).

Jednačenje po mjestu tvorbe u sandhi-položaju potvrđuje se primjerima bež nje 61 i ž num 21. To je razvidno i u staroj kajkavskoj književnosti, a i u suvremenih turopoljskih govora (Šojat 1982: 363, 2009: 38).

Neprovođenje sekundarne jotacije potvrđuje se primjerima v cvietju 23, listju 53, a u primjeru z proleča 45 ona se provodi. U staroj kajkavskoj književnosti nema nijedne potvrde za promjenu $t j>\check{c}$, međutim, u suvremenim turopoljskim govorima rijetki su primjeri za navedenu pojavu (Šojat 1982: 359, 2009: 33).

U tekstu se potvrđuje samo nepremetnuta i nejotirana suglasnička skupina $j d \mathrm{u}$ prefigiranim oblicima glagola iti, npr. duojdi 53, noajdem 41. Pojava je redovita u staroj kajkavskoj književnosti i u suvremenim turopoljskim govorima (Šojat 1982: 359, 2009: 34).

Suglasnik j gubi se u suglasničkoj skupini žj, npr. Buoži poasec 49. U staroj kajkavskoj književnosti u toj se suglasničkoj skupini $j$ pretežito čuva, dok je njegovo gubljenje redovito u suvremenih turopoljskih govora (Šojat 1982: 358, 2009: 35).

Autorica nije dosljedna kod bilježenja završnoga i početnoga $v$, npr. gizdaf 51, lubaf 27, uprof 33; lubav 13, 71, uprav 39; fkrola 63; vkroala 77, vtuči 51. Promjenu $v>f$ stari kajkavski pisci ne bilježe, ali je ona živa u suvremenim turopoljskim govorima (Šojat 1982: 357, 2009: 21). 
Prijedlog $v$ se čuva, ali kada je uz zamjenicu ili riječ s početnim $v$, onda se javlja vu, npr. v krilu 11, v nepovrat 75, v nutrine 13, v utrobe 15, v zemlu 39; vu mene 13, 19, vu se 71, vu te 25, 43, vu tebe 25, vu vrbove krošnje 37. Ista je situacija u jeziku starih kajkavskih pisaca i suvremenih turopoljskih govora (Šojat 1982: 344, 2009: 15).

Prijedlog $s$ javlja se triput, a prevladava $z$ u značenju "s, sa" i "iz, npr. $s$ bisagami 69, s velikim zrcalom 63, s žirom 65; z črnoga oblaka 67, z hižice 29, z korejnem 13, z peči 29 , z tuobom 25 , z turopolskoga luga 65 , z voami 17 . Samo $\mathrm{u}$ jednom primjeru potvrđuje se ze, npr. pučem te ze zaborava 19. Potvrde sa $z$ zajednička su svojina starih kajkavskih pisaca i suvremenih turopoljskih govora (Šojat 1982: 351, 363, 2009: 18).

Promjenu zgj > žđ nalazim u dvama primjerima: možđane 61, možđani 29. To je potvrđeno i u starih kajkavskih pisaca i suvremenih turopoljskih govora (Šojat 1982: 362, 2009: 32).

\section{Morfološke osobitosti}

Imenice $\mathrm{m}$. roda $\mathrm{u} \mathrm{V}$ jd. na tri mjesta imaju nastavak - $e$, vezan uz imenicu Bog: Bože 23, 39, 63, ali: Bogek 63. U jeziku stare kajkavske književnosti riječ Bog ima poseban vokativni oblik Bože, a u suvremenim turopoljskim govorima on izostaje (Šojat 1982: 388, 2009: 47). Imenice m. i sr. roda u L jd. imaju nastavak -u, npr. v cvietju 23, v krilu 11, po nebu 33, na šporetu 29, na vetru 55, v žitku 17; u N mn. imenice m. roda imaju kratke oblike, npr. plači 27, vetri 35; u G mn. nastavak -ov: žgancov 39; imenice sr. roda u D mn. nastavak -am: ne da se lietam vtuči 51; u L mn. -e, npr. po možđane 61, na pleče 47; u I mn. -i, npr. med prsti 25, z pogledi 49. U jeziku stare kajkavske književnosti potvrđeni su svi nastavci, osim navedenoga u L mn. (Šojat 2009: 44). Razlog toj pojavi leži u činjenici što je kajkavski književni jezik, u odnosu na kajkavske govore, vjerno sačuvao glas $h$ u svim položajima unutar riječi. Svi su nastavci potvrđeni i u suvremenim turopoljskim govorima (Šojat 1982: 387-393).

Imenice ž. roda u DL jd. imaju nastavak -e, npr. mamice 29, 41, pri duše 29, v nutrine 13, po steze 53, v utrobe 15; za V jd. nalazim samo potvrdu: grudo zemle 57; u I jd. -um, npr. bukum 33, pečenicum 63, ravnicum 77, ticum 33; u $\mathrm{D}$ mn. nalazim samo jednu potvrdu s nastavkom -am: $k$ vuličkam vuskem 37; $\mathrm{u}$ L mn. stari nastavak - $a(h)$ i analoški -ami, npr. (vu) Vukomeričke gorica 43, v ruka 25, po knigami 21; u I mn. potvrđuje se nastavak -ami, npr. s bisagami 69, z koantami 47. U jeziku stare kajkavske književnosti potvrđeni su svi nastavci, osim navedenih za V jd. -o i L. mn. - $a$ (Šojat 2009: 44). Svi navedeni nastavci, uključujući i one za V jd. i L mn., potvrđuju se u suvremenim turopoljskim 
govorima (Šojat 1982: 395-396).

Naglašeni oblici ličnih zamjenica ja i ti u DL glase mene i tebe, npr. ti si mene droaga 63 , $k$ tebe 25 , vu mene 13, 19, 27, vu tebe 25; u I tuobom 25 . U jeziku stare kajkavske književnosti i suvremenih turopoljskih govora ista je situacija, osim u I gdje se pretežito potvrđuje oblik tobum (Šojat 1982: 402, 2009: 66). Oblik tuobom autorica preuzima iz štokavskih izvora.

Naglašeni oblik lične zamjenice ona u L glasi jne, u I njum, a nenaglašeni oblik u D je, a A ju, npr. vujne (= u njoj) 39, pred njum 67; orehnaču sem je spekla 59, ki bi je reči mogel 77; šibaju ju vetri 35, čutim ju v sake pore 61, muči ju mora 77. U jeziku stare kajkavske književnosti i suvremenih turopoljskih govora ista je situacija (Šojat 1982: 403, RHKKJ 2002: 505).

Zamjenica mi u L ima analoški nastavak prema instrumentalu: vu nomi 23. Zamjenice mi i vi u I imaju oblike: noami 23 i voami 17. U jeziku stare kajkavske književnosti ista je situacija, osim u L gdje se čuva stari oblik nas (RHKKJ 1991: 649). U suvremenim turopoljskim govorima svi autoričini oblici jesu potvrđeni (Šojat 1982: 402).

Povratna zamjenica u L glasi sebe 73, a u I suobom 33. U jeziku stare kajkavske književnosti i suvremenih turopoljskih govora ista je situacija, osim u I gdje se pretežito potvrđuje oblik sobum (Šojat 1982: 402, 2009: 66). Oblik suobom autorica preuzima iz štokavskih izvora.

Od neličnih oblika zamjenica izdvajam: L jd. m. roda, npr. $v$ tem času 53, vu tiem 63; L jd. ž. roda, npr. v bistrine tvoje 55, v utrobe tvoje 15, v sake pore $61, v$ sake žile 17 , po svoje pameti 29 , vu te klieti 43 ; I jd. m. roda, npr. z kiem 63, za siem 67; I jd. ž. roda, npr. ovum 77, stum 33, svojum 33. U jeziku stare kajkavske književnosti i u suvremenih turopoljskih govora potvrđuju se svi navedeni oblici (Šojat 1982: 402-405, 2009: 59, 61).

Zamjenica kaj potvrđuje se istim oblikom: kaj 15, 17, 21, 67 (u priloga: zoakaj 29, 77). Na tri mjesta javlja se štokavski oblik: niš 39, ništa 35, 47. Štokavski oblici niš i ništa potvrđuju se i u jeziku stare kajkavske književnosti i u suvremenih turopoljskih govora (Šojat 1982: 405, RHKKJ 1999: 282-283).

Od pridjeva izdvajam: L jd. m. i sr. roda, npr. po cielem svietu 33, po cielom svietu 33, v maminom krilu 25, L jd. ž. roda, npr. po nebeske glibline 21, po stoare škrijne 41, vu vrbove krošnje 37; I jd. m. i sr. roda, npr. pred Ježušekovem raspelom 43, z mirisom opojnem 49, z velikim zrcalom 63; I mn. m. roda, npr. med živemi i mrtvemi 77. Svi navedeni oblici 
potvrđuju se u jeziku stare kajkavske književnosti i suvremenih turopoljskih govora (Šojat 1982: 398, 2009: 59).

Zabilježen je samo jedan komparativ: buolšega 69. Prilog nastao od komparativa pridjeva također je zabilježen jednim primjerom: glipše (= dublje) 25, 41. Zabilježen je samo jedan superlativ koji se tvori tako da se komparativu s nastavkom -eši doda čestica naj-: noajmilešu 71. U jeziku stare kajkavske književnosti i u suvremenih turopoljskih govora potvrđuje se oblik glibok i njegove izvedenice, kao i komparativni oblik bolši (Šojat 1982: 401, 2009: 63, RHKKJ 1986: 614).

Svršeni prezent glagola biti ima samo kraće oblike, npr. bu 19, buš 63, bumo 25. Zanijekani nesvršeni prezent istoga glagola u 1. 1. jd. glasi nisem: nisem smiela 41, u 3. 1. jd. ni: vrbe tu više ni 37, japek naš to ni 41, ni napustil 51, požalila ni 35. U 1. 1. mn. prezenta potvrđuju se oblici sa završnim -u, npr. sedimu joa i ti 23 , moaramu se žuriti 59. U 3. 1. mn. najčešće se provodi analogija prema 2. 1. mn., npr. moamiju ga ruože 49, pritiščeju 69, ali: vškolu idu dečica 29.

Pri tvorbi futura drugog autorica redovito rabi kratke oblike svršenoga prezenta pomoćnoga glagola biti, npr. bum lubil 63, bum našla 25, vikala bum 19, bum vikala 19, bumu ponesle 59.

Od imperativnih oblika izdvajam: 2. 1. jd. dej 33, 43, gleč 41, hodi 59, noaj (= nemoj) 33, pomozi 63; 3. 1. jd. nek preklije 15, nek mu oprosti 47, nek si gukne 59; 2. 1. mn. glečte 39, rečete 17, verujte 63, vrnete 77.

Od kondicionala prvog potvrđuju se samo oblici za 1. i 3. 1. jd., npr. bi smiela 35, bi štela 35, bi štiela 25, bi zašla 25; bi del 69, bi štel 69, bi vozil 63.

Glagolski prilog sadašnji potvrđuje se nastavkom -č, npr. hodeč 37, sedeč 33 .

Od svih navedenih glagolskih oblika potvrđuju se svi u jeziku stare kajkavske književnosti, osim prezentskoga nastavka sa završnim - $u$ (Šojat 2009: 73, 81, 83-85, 88). U suvremenih turopoljskih govora također se potvrđuju svi glagolski oblici, osim 3. 1. jd. imperativa gdje se rabi čestica naj (Šojat 1982: 406-418). Česticu nek u 3. 1. jd. imperativa autorica preuzima iz štokavskih izvora. 


\section{Zaključak}

Uspoređujući autoričinu pisanu građu sa stanjem u jeziku stare kajkavske književnosti (a) te u suvremenim turopoljskim govorima (b) možemo očekivati četiri moguće situacije: 1 . jezične osobitosti koje su zajedničke (a) i (b), 2. jezične osobitosti vezane samo uz (a), 3. jezične osobitosti vezane samo uz (b), 4. jezične osobitosti koje ne pripadaju ni (a) ni (b).

$\mathrm{Na}$ fonološkom i morfološkom planu u istraženoj građi najčešće se potvrđuju osobitosti pod rednim brojem 1 .

Pod rednim brojem 2. nalazim potvrdu samo na morfološkom planu (V jd. grudo), a isto vrijedi i za pojavu pod rednim brojem 4. (riječ je o oblicima tuobom, suobom i nek).

Najzanimljivije su one potvrde pod rednim brojem 3., dakle fonološke i morfološke osobitosti tipične za suvremene turopoljske govore, a nepotvrđene ili vrlo rijetko potvrđene u jeziku stare kajkavske književnosti, a to su: promjena $a>e$ (rezmieče, dej), promjena $e>i e$ (kapielica), promjena $o>$ uo (muoj, duojdi), gubljenje početnoga i završnoga $h$ (očemo, $v$ ruka, po možđane), promjena ń $>$ jn (kojnek, sejna), promjena $d n>n$ (jen, jena), promjena $k t>t$ (teri), promjene $p \check{s}>\check{s}$ i $p t>t$ (šenica, tica), promjene $v \check{c}>\check{c}, v n>n, v s>s, v z>z$ (čera, nučica, saki, zela), obezvučenje završnoga zvučnog suglasnika (vrak), sekundarna jotacija u svezi sa skupinom $t j$ (proleče), promjena $\check{z} j>\check{z}$ (Buoži), promjena $v>f$ (gizdaf, fkrola); nastavak -o u V jd. imenica ž. roda (grudo), nastavak -e u L mn. imenica sr. roda (po možđane), nastavak - $a \mathrm{u} \mathrm{L} \mathrm{mn.} \mathrm{imenica} \mathrm{ž.} \mathrm{roda} \mathrm{(} v$ ruka), analoški oblik vami u L, nastavak $-u$ u 1. 1. mn. prezenta.

\section{LITERATURA}

***2006. Kajkavska poezija udruge umjetnika Spark - Velika Gorica. Kaj, 1-2: 12-20.

Jandriš-Parać, Đurđa. 2005. Turopole moje lepo: joa i ti-jeno zanaviek. Velika Gorica: Udruga umjetnika Spark.

Junković, Zvonimir. 1956. Izvještaj o istraživanju kajkavskoga dijalekta u zagrebačkoj okolici. Ljetopis JAZU, 61: 391-395.

Junković, Zvonimir. 1982. Dioba kajkavskih govora: porodice, tipovi i savezi. Hrvatski dijalektološki zbornik, 6: 191-216.

Kekez, Stipe. 2007. O istraživanju turopoljskih govora. Kaj, 6: 53-66.

Šojat, Antun. 1963. Izvještaj o istraživanju govora u Turopolju. Ljetopis JAZU, 67: 310-315. 
Šojat, Antun. 1963. Izvještaj o istraživanju turopoljskih govora izvršenom 1961. godine. Ljetopis JAZU, 68: 310.

Šojat, Antun. 1967. Položaj turopoljskih govora u hrvatskoj kajkavštini. Zbornik za filologiju i lingvistiku Matice srpske, 10: 147-153.

Šojat, Antun. 1982. Turopoljski govori. Hrvatski dijalektološki zbornik, 6: 317-493.

Šojat, Antun. 2009. Kratki navuk jezičnice horvatske. Jezik stare kajkavske književnosti. Institut za hrvatski jezik i jezikoslovlje. Zagreb: Institut za hrvatski jezik i jezikoslovlje.

\section{ABOUT ĐURĐA JANDRIŠ-PARAĆ'S KAJKAVIAN POETRY LANGUAGE}

By Boris Kuzmić, Zagreb

\section{Summary}

The paper analyses the language of the Kajkavian poetry collection Turopole moje lepo: joa i ti-jeno zanaviek (2005) by Đurđa Jandriš-Parać (1945). The analysis will show to what extent the author's modern Kajkavian literary language includes diachrony (knowledge of the old Kajkavian literature language) and synchronicity (contemporary Turopolje speeches, especially the Pleso speech, of which the paper's author is a native speaker).

Key words: Kajkavian poetry; Kajkavian literary language; Đurđa Jandriš-Parać; Pleso; Turopolje

Prijevod: autor 